\title{
Telemetric monitoring in the behavior sciences
}

\author{
Matrhew S. Goodwin and Wayne F. Velicer \\ University of Rhode Island, Kingston, Rhode Island \\ AND \\ STEPHEN S. INTTLLE \\ Massachusetts Institute of Technology, Cambridge, Massachusetts
}

\begin{abstract}
This article reviews recent advances in telemetrics, a class of wireless information systems technology that can collect and transmit a wide variety of behavioral and environmental data remotely. Telemetrics include wearable computers that weave on-body sensors into articles of clothing, ubiquitous computers that embed sensors and transmitters seamlessly into the environment, and handheld devices, such as mobile phones and personal digital assistants, that can record cognitive and affective states. Examples of telemetric applications are provided to illustrate how this technology has been used in the behavioral sciences to unobtrusively and repeatedly gather physiological, behavioral, environmental, cognitive, and affective data in natural settings. Special issues relating to privacy and confidentiality, practical considerations, and statistical and measurement challenges when telemetrics are used are also discussed.
\end{abstract}

The majority of research in the behavioral sciences has employed cross-sectional study designs that collect data from a large number of people at a single point in time in a limited number of settings (Molenaar, 2004). To appreciate contextual and temporal patterns of human behavior (McGrath \& Tschan, 2004), intensive longitudinal designs (Walls \& Schafer, 2006) are needed to gather data on individuals, repeatedly over extended periods of time, in a wide range of settings. Intensive longitudinal studies have the potential to detect underlying natural behavior processes, characterize patterns of change over time, and evaluate the effects of either a planned or an unplanned intervention. Intensive longitudinal studies utilizing repeated measurements can also establish temporal precedence between variables and help in the determination of causeeffect relations. Increasing the number of observations also increases the power of longitudinal designs. Although intensive longitudinal studies are clearly advantageous in many ways, there is a key problem relating to their use: They require quantitative measures that can sample a large number of behaviors and events in natural settings.

This review describes an emerging class of information systems technology called telemetrics that behavioral scientists can use to gather the types of data needed for intensive longitudinal studies. Generally, telemetrics include passive and active wireless technologies that collect and transmit data remotely. Passive telemetrics include wearable and ubiquitous computers that record behavioral, physiological, and environmental data from sensors worn on the body or embedded in the environment. Active telemetrics include handheld devices, such as mobile phones and personal digital assistants (PDAs), that allow a user to record and receive cognitive and affective information.

This review is organized in the following manner. The first section discusses three key measurement issues in the behavioral sciences that may be addressed with telemetric technology. The second section provides a general overview of telemetrics, including advances in wearable, ubiquitous, and handheld computing technology. The third section discusses the advantages of using telemetrics for behavioral assessment and illustrates, with applied examples, how this technology has been used to measure and intervene on a wide variety of behaviors in natural settings. The final section discusses ethical, practical, statistical, and measurement issues that must be considered when telemetrics are used and highlights future research needed in these areas.

\section{MEASUREMENT ISSUES IN THE BEHAVIORAL SCIENCES}

Ecological validity, repeated assessments, and reactivity to measurement represent three key issues relevant to behavioral assessment strategies in the behavior sciences. The present section will briefly review each of these issues and will suggest that assessment procedures are needed to unobtrusively measure behavior repeatedly in natural environments.

\section{Ecological Validity}

Ecological validity, in the broadest sense, refers to the relation between the assessment of behavior in experimental contexts and behavior as it is produced in situ (Brunswik, 
1947). Often used synonymously with generalizability, ecological validity connotes representativeness or naturalness. In a concise review of the concept, Schmuckler (2001) highlights three dimensions of ecological validity relevant to behavioral assessment. The first dimension stresses real-world generality and the importance of making assessments in a setting in which a person behaves on a regular basis (Bronfenbrenner, 1977, 1979). The second dimension relates to the stimuli under investigation and emphasizes the importance of observing temporally and spatially relevant variables that reliably produce the behavior of interest in natural settings (Neisser, 1976). The third dimension focuses on the nature of the task, behavior, or response performed by the research participant and stresses the importance of observing behavior that is both most relevant for investigation and indicative of a person's behavioral repertoire (Bronfenbrenner, 1977, 1979). Taken together, the most ecologically valid behavior assessment strategy is one that makes observations in the real world where behavior, and all of its structural and functional relationships, occurs naturally.

\section{Repeated Assessments}

As developmentalists have long maintained, each person's behavior represents a potentially unique, dynamic process that fluctuates over time and across situations (Baltes, Reese, \& Lipsitt, 1980; Baltes, Reese, \& Nesselroade, 1988). However, traditional behavior assessment strategies often fail to conceptualize or sample behavior in this way. Behavioral science research has been, and continues to be, dominated by the group comparison or nomothetic approach that focuses on population averages captured at one or a few time points, using a limited number of dependent variables (Danziger, 1990; Lamiell, 2003). In response to this trend, some behavioral scientists have advocated a single-case or idiographic approach to sampling behavior that focuses on the prospective, multivariate, time-dependent variation within individuals (Allport, 1961, 1962; Barlow \& Hersen, 1984; Broverman, 1962; Cone, 1986; Epstein, 1983; Kazdin, 1992; Lamiell, 1981, 1987; Molenaar, 2004; Molenaar, Huizenga, \& Nesselroade, 2003; Nelson-Gray, 1996; Nesselroade \& Ghisletta, 2003; Pervin, 1984; Velicer \& Fava, 2003; Wilson, Hopkins, de Vries, \& Copeland, 1992). There are several advantages associated with an idiographic approach. First, its in-depth and multivariate approach to data collection honors the full environmental, social, and historical contexts that influence behavior. Second, as time is sampled more intensively, idiographic measurement can characterize patterns of change (temporal configurations) over time. Third, time-intensive idiographic studies enable the capturing of proximal events and behaviors closer to their actual occurrence and the tracking of changes in rapidly fluctuating processes. Finally, repeated measurement of behavior can establish temporal precedence as a foundation for causal inference.

\section{Reactivity to Measurement}

Put simply, reactivity refers to the phenomenon of measurement processes actually producing change in what is measured (Campbell \& Stanley, 1966). Early reviews have suggested that reactivity to measurement can influence behavior in a number of important ways (for reviews, see Campbell \& Stanley, 1966; Cook \& Campbell, 1979; Harris \& Lahey, 1982; Haynes \& Horn, 1982; Johnson \& Bolstad, 1973; Kazdin, 1979a, 1979b, 1982; Kent \& Foster, 1977; Lipinski \& Nelson, 1974; Patterson \& Sechrest, 1983; Shadish, Cook, \& Campbell, 2002; Webb, Campbell, Schwartz, Sechrest, \& Grove, 1981). Obtrusive measurement can act as a change agent itself, so that the measurement process, rather than the experimental variables under study, produces behavioral change. For example, obtrusive assessment procedures can increase the salience of a person's behavior and result in self-regulation, so that positively valenced behaviors increase while negatively valenced behaviors decrease. Reactive assessments can create evaluation apprehension (Rosenberg, 1969), resulting in the studied individuals' responding in ways inviting approval from the experimenter. Also, in terms of response sets, reactivity can manifest itself as acquiescence, so that people endorse any statement, even those of opposite meaning (Cronbach, 1946).

Behavioral reactivity can threaten various types of validity in behavior assessments (Cook \& Campbell, 1979; Shadish et al., 2002). Reactivity can threaten internal validity by causing systematic changes in behavior from one assessment occasion to another, quite unrelated to the independent variable(s) under study. Reactivity can threaten external validity if the behavior observed does not generalize to conditions (e.g., persons, situation, and measures) beyond those used in the investigation. Finally, construct validity can be threatened if behavioral differences are caused by increased evaluation apprehension or expectancies for change.

An obvious strategy for reducing the effects of behavioral reactivity is to use observation procedures that involve little or no alteration of environmental stimuli and that minimize evaluation apprehension. Investigators concerned with measurement reactivity have long advocated unobtrusive observation procedures and have suggested that less reactive forms of behavior be recorded and that discrete, equipmentbased capture technology be used. Some of the less reactive forms of behavior suggested include nonverbal actions, such as noncontent aspects of speech (e.g., voice volume, speech rate, and utterance length), physiological responding, facial expressions, kinetics or body movements, visual behavior, and human use of space; all of which can indicate social behaviors and individual personality characteristics and affective and attitudinal states (for reviews of unobtrusive measures, see Harper \& Wiens, 1979; Kazdin, 1979a, 1979b; Patterson \& Sechrest, 1983). Some of the less reactive observation technologies that have been suggested have included discretely mounted video cameras and microphones capable of recording visible and audible behavior and microcomputers capable of conducting interviews (Erdman, Klein, \& Greist, 1985), tailoring psychological tests (Burke \& Normand, 1987), capturing and coding observational data (Farrell, 1991), and recording physiological data ambulatorily (Burnett, Taylor, \& Agras, 1985).

In the remainder of this article, we will review advances in telemetric technology that have the potential to address these behavioral assessment issues by enabling repeated assessments of behavioral, physiological, cognitive, and affective processes unobtrusively in natural settings. 


\section{TELEMETRICS}

Telemetrics utilize both passive and active technology to wirelessly measure and transmit a wide variety of data from remote locations. Passive telemetrics record behavioral, physiological, and environmental data automatically from sensors worn on the body or embedded in the environment. Active telemetrics gather self-reported cognitive and affective information using handheld devices, such as PDAs or mobile phones. For both classes of equipment, the input or signal is quantified and combined with timing data, resulting in a single data stream for researchers to explore.

\section{Passive Telemetrics}

In the past 10 years, researchers in academia (e.g., Massachusetts Institute of Technology, Georgia Tech, Carnegie Mellon, Stanford, among others), government (e.g., NASA, among others), and industry (e.g., Intel, Hitachi, Vivometrics, among others) in the United States, Europe, Australia, and Asia have developed wireless technologies that can be integrated into clothes and mounted discreetly in the environment. These two initiatives have shaped emerging computer science and engineering fields, known as wearable computing (or wearables) and ubiquitous computing (or ubicomp).

Wearable computing. Breaking away from the traditional desktop computer paradigm, computer scientists are actively developing computational systems that are as mobile as their users (Starner, 2001). The extreme process of miniaturization in both electronic circuits and processors are enabling passive (i.e., not requiring conscious input from the wearer), on-body perception systems to be sewn into articles of clothing and embedded into wearable accessories, such as shoes, gloves, and jewelry (Asada, Shaltis, Reisner, Rhee, \& Hutchinson, 2003; Poli, 2003; Starner, 2002; Wilhelm, Roth, \& Sackner, 2003). For example, small, wireless physiological sensors have been developed to unobtrusively record cardiovascular, respiratory, skin conductivity, and muscle activity in freely moving people (see Figures 1 and 2; see Healey, 2000, for an overview of these sensors). Miniature actigraphs and accelerometers capable of objectively quantifying physical activities, including body postures (e.g., lying, sitting, or standing) and dynamic activities (e.g., walking, climbing stairs, or postural transitions) are being embedded in wrist bands, bracelets, and belts (Bao \& Intille, 2004). Audio capture technologies that utilize small, unobtrusive microphones are being integrated into wearable computing platforms to record sounds created by the user (e.g., speech or gestures) and ambient auditory events in the environment (Mehl, Pennebaker, Crow, Dabbs, \& Price, 2001; Stager et al., 2003). And discreet, infrared-sensitive cameras are being integrated into eyeglasses to determine where a user is looking and what he or she is looking at (Dickie et al., 2004; Vertegaal, Slagter, van der Veer, \& Nijholt, 2001).

Ubiquitous computing. In 1991, Mark Weiser, head of the Computing Science Laboratory at the Xerox Palo Alto Research Center, introduced the area of ubiquitous computing when he suggested that technologies be devel-

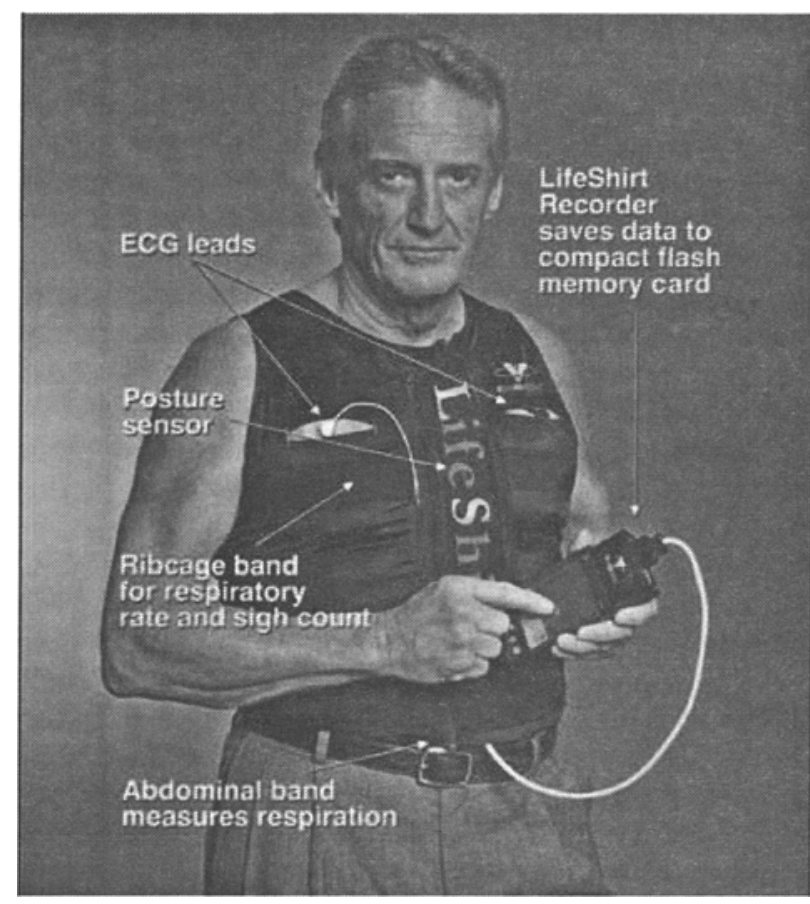

Figure 1. The LifeShirt is a lightweight (8 oz.), machine washable, comfortable shirt with embedded sensors. To measure respiratory function, sensors are woven into the shirt around the chest and abdomen. A single-channel ECG measures heart rate, and a three-axis accelerometer records posture and activity level. Optional peripheral devices measure blood pressure, blood oxygen saturation, and other physiologic parameters. The LifeShirt System includes an integrated personal digital assistant that continuously encrypts and stores physiologic data on a compact flash memory card. Wearers may also record time/date-stamped symptom, mood, and activity information in the recorder's digital diary, allowing researchers and clinicians to correlate subjective patient input with objectively measured physiologic parameters. See vivometrics.com.

oped that "weave themselves into the fabric of everyday life until they are indistinguishable from it" (Weiser, 1991, p. 94). Since Weiser's decree, researchers have embedded ubiquitous sensing technologies in the environment to develop living laboratories and smart rooms capable of wirelessly and passively monitoring surroundings and inhabitant behavior (Abowd et al., 2000; Intille et al., 2005; Pentland, 1996). Dense arrays of unobservable telemetric sensing devices are typically embedded in these settings to record interior conditions, such as temperature, humidity, light, and barometric pressure (see Figure 3). Discretely mounted microphones, video cameras, and motion sensors are used to record what people say, what activities they are involved in, and where they go (see Figure 4). And even less obtrusive sensors, including force-sensitive load tiles to identify and locate a person solely on the basis of his or her footsteps (Kidd et al., 1999; Orr \& Abowd, 2000), radio frequency identification tags ${ }^{1}$ (RFIDs) attached to common items to detect person-object interactions (Fishkin, Jiang, Philipose, \& Roy, 2004; Munguia Tapia, Intille, \& Larson, 2004), and global positioning system (GPS) sensors that can measure a person's location and movements (Ashbrook \& Starner, 2003), are being explored. 


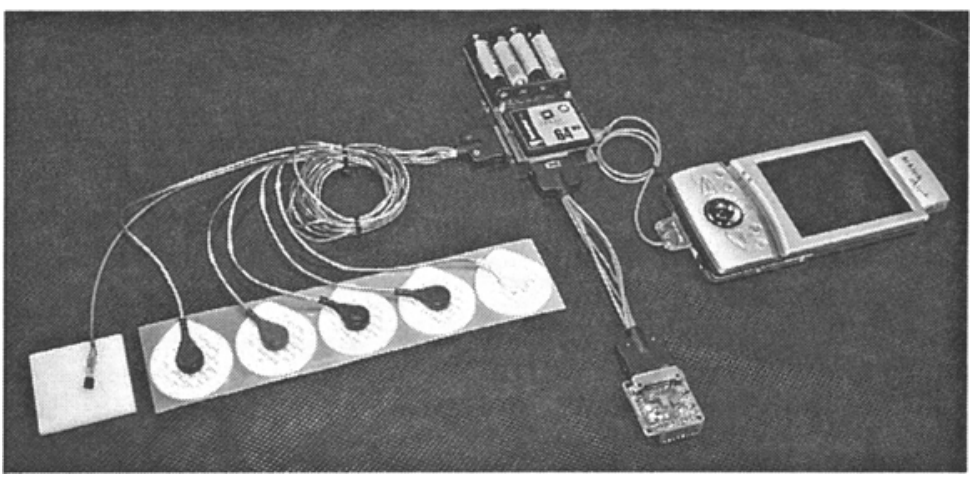

Figure 2. MIThril system, composed of the Zaurus PDA (right) with Hoarder sensor hub and physiological sensing board (top), EKG/EMG/GSR/temperature electrodes and sensors (left), and combined three-axis accelerometer and infrared tag reader (bottom). From "LiveNet: Health and Lifestyle Networking Through Distributed Mobile Devices," by M. Sung and A. Pentland, 2004, presented at MobiSys 2004: Workshop on Applications of Mobile Embedded Systems (WAMES 2004). Reprinted with permission.

All of these sensing devices can automatically and continuously relay their recordings to a nearby network of computers to produce a single, synchronized data set.

\section{Active Telemetrics}

A growing number of researchers in the behavioral sciences are also using palmtop computers, PDAs, and mobile phones equipped with specialized, configurable software that enables participants to answer questions about their experiences and share cognitive and affective information in natural settings, in real time (or close to the moment of reported experience), and on repeated occasions (see Barrett \& Barrett, 2001; Conner, Barrett, BlissMoreau, Lebo, \& Kaschub, 2003; Shiffman, 2000). This collection of procedures, called computerized experiencesampling methods (ESMs; see Conner, Barrett, Tugade, \& Tennen, 2007, for an excellent overview of ESM methods), includes ecological momentary assessment (Stone \& Shiffman, 1994), diary methods (Bolger, Davis, \& Ra- faeli, 2003), and daily process methods (Tennen, Affleck, \& Armeli, 2003). ESM allows people either to initiate self-reports that are automatically time and date stamped or to respond within a short window when cued by the device with an audible or vibrotactile prompt. In either case, entered data are stored on the device and uploaded manually or transferred wirelessly to a master computer for researchers to explore.

\section{TELEMETRIC MONITORING IN THE BEHAVIORAL SCIENCES}

Utilizing handheld devices and wearable and ubiquitous sensors, behavioral scientists can now configure sophisticated methodological tools for telemetrically monitoring an individual's behavioral, cognitive, affective, and physiological responses repeatedly in a wide range of settings (for an excellent review, see Intille, 2007). For instance, Nusser, Intille, and Maitra (2006) claimed that,
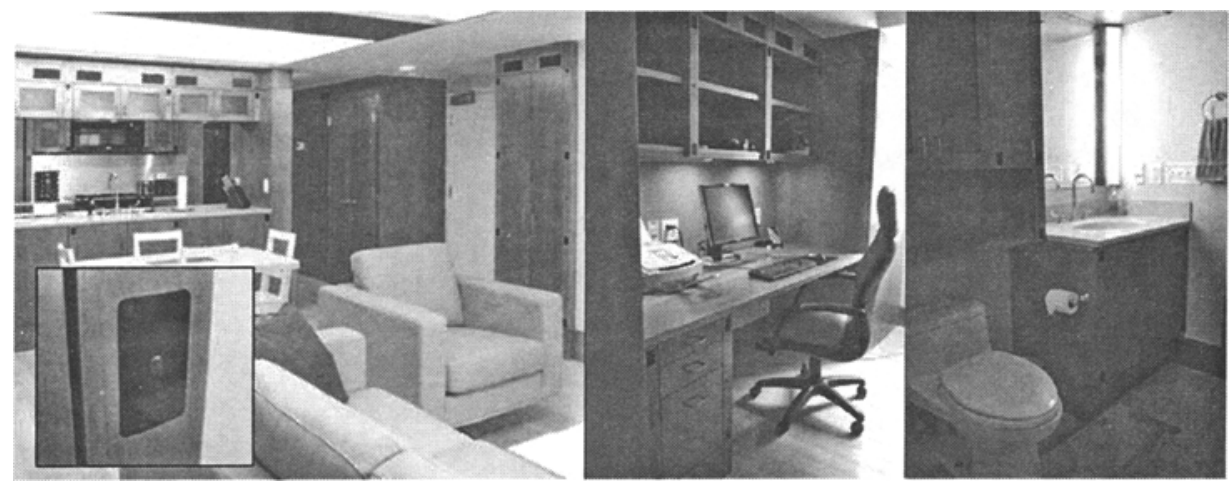

Figure 3. The PlaceLab living room and kitchen, office, and master bath. All of the observational sensing is built directly into the cabinetry. Although the sensors are ubiquitous, they become part of the design aesthetic (small black windows). The inset in the left image shows a microphone. From "A Living Laboratory for the Design and Evaluation of Ubiquitous Computing Technologies," by S. S. Intille, K. Larson, J. S. Beaudin, J. Nawyn, E. M. Tapia, and P. Kaushik, 2005. In CHI '05: Extended Abstracts on Human Factors in Computing Systems. New York: ACM Press. Copyright 2005 by ACM. Reprinted with permission. 


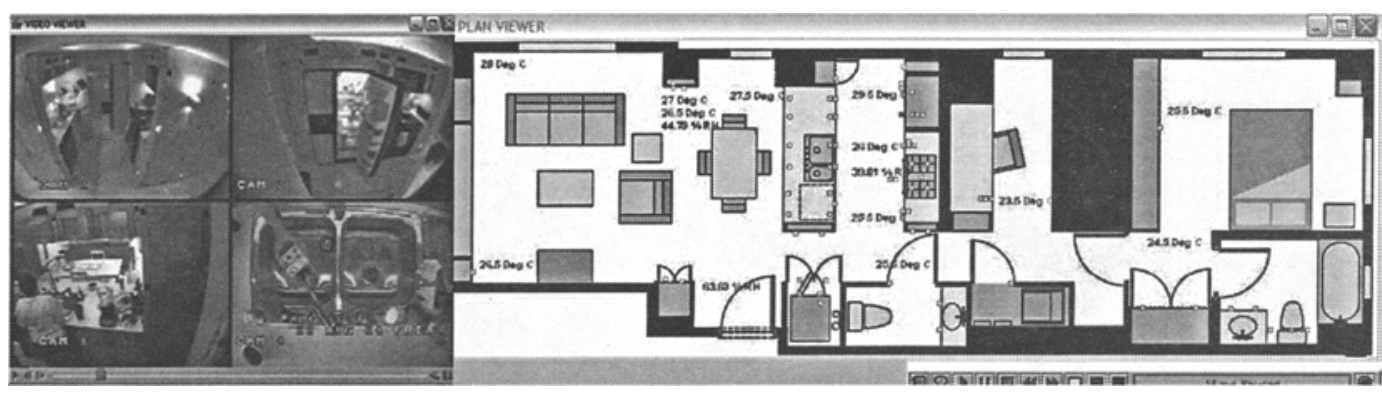

Figure 4. Annotation software permits the researcher to study data collected from the PlaceLab by watching four streams of video, listening to one audio stream, and displaying sensor activations on a foor plan of the environment. Here, the floor plan shows all switch sensors currently installed in the lab (small dots) and temperature sensor output. The researcher can use particular sensor activations to reduce search and annotation time. From “A Living Laboratory for the Design and Evaluation of Ubiquitous Computing Technologies," by S. S. Intille, K. Larson, J. S. Beaudin, J. Nawyn, E. M. Tapia, and P. Kaushik, 2005. In CHI '05: Extended Abstracts on Human Factors in Computing Systems. New York: ACM Press. Copyright 2005 by ACM. Reprinted with permission.

With the technology available today, a comfortable device can be created that collects continuous streams of video data describing everything the subject sees, audio data of everything the subject hears and says, accelerometer data of the subject's limb motion, data on physiological parameters such as heart rate, data on the subject's location in the community, as well as other miscellaneous data about how the subject is feeling, as reported by the subject via a mobile computing device user interface. (p. 254)

All this information can be simultaneously recorded, time stamped, and synchronized so that contextual and temporal relationships can be ascertained and verified.

Telemetric monitoring supports four key advances in behavioral assessments. First, telemetric sampling devices can store an unprecedented amount of longitudinal data appropriate for idiographic analyses. Second, discrete, wireless sensors worn on the body and embedded in the environment can decrease measurement reactivity and increase ecological validity by recording information about a freely moving person's location, intensive physiological states, and activities comfortably, continuously, and passively. Third, when self-reports are desired, researchers can configure a context-aware mobile computing device that integrates passive sensors (e.g., heart rate, GPS, or accelerometry) with handheld devices to issue a prompt for more information only when a person is in a specific location, engaged in a particular activity, or experiencing a certain behavioral or physiological response (see Intille, Rondoni, Kukla, Iacono, \& Bao, 2003). Finally, pattern recognition algorithms (Theodoridis \& Koutroumbas, 2006; Witten \& Frank, 1999) can run on context-aware mobile computing devices to tailor questions, trigger a response, or provide feedback on the basis of a person's physical and physiological patterns, reported subjective states, or interpersonal experiences (see Figures 5 and 6; Intille, 2002; Picard, 1997).

\section{Examples of Behavioral Science Applications}

A few applications of telemetric monitoring are presented below to illustrate how this technology can en- hance efforts to measure and intervene on a wide variety of behaviors in natural settings.

Stress and autism. Autism spectrum disorders (ASDs) are a collection of neurodevelopmental disorders characterized by qualitative impairments in socialization, communication, and circumscribed interests, including stereotypical behavior patterns and behavioral rigidity to changes in routines (American Psychiatric Association, 1994). Current epidemiological studies of ASD suggest a rate as high as 1/166 (Fombonne, 2003; Yeargin-Allsopp et al., 2003), translating into approximately 425,000 children younger than 18 years of age in the United States (Fombonne, 2003). ASDs typically manifest in infancy and persist throughout the lifespan. These disorders have a profound impact on families and often result in enormous emotional and finan-

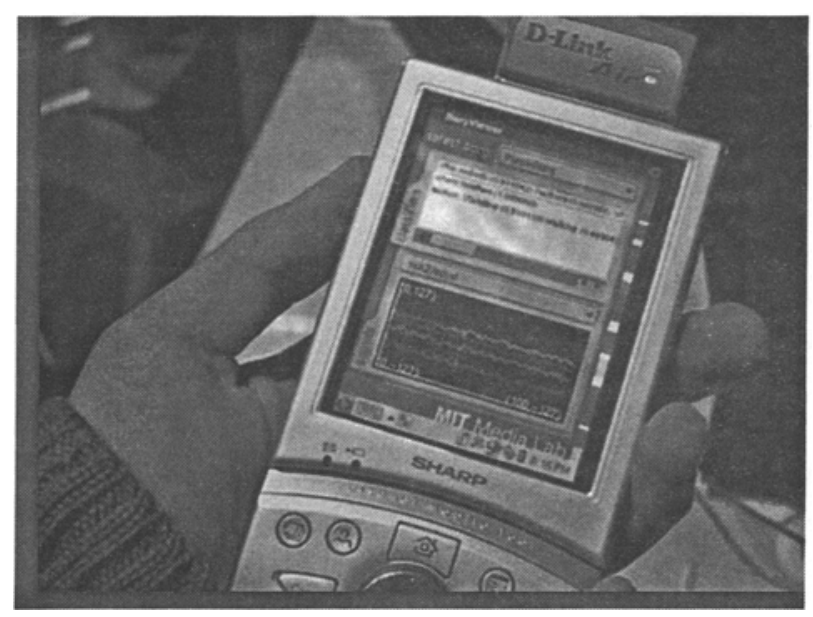

Figure 5. MIThril LiveNet wearable performing real-time analysis and activity classification on accelerometer data and visualizing the results, as well as wirelessly streaming real-time EKG/ GSR/temperature and classification results to a remote computer with a projection display, as well as to peer LiveNet systems that may be anywhere in the world. From "Wearable Feedback Systems for Rehabilitation," by M. Sung, C. Marci, and A. Pentland, 2005, Journal of NeuroEngineering \& Rehabilitation, 2, p. 17. Copyright 2005 by Sung et al.; licensee BioMed Central Ltd. Reprinted with permission. 


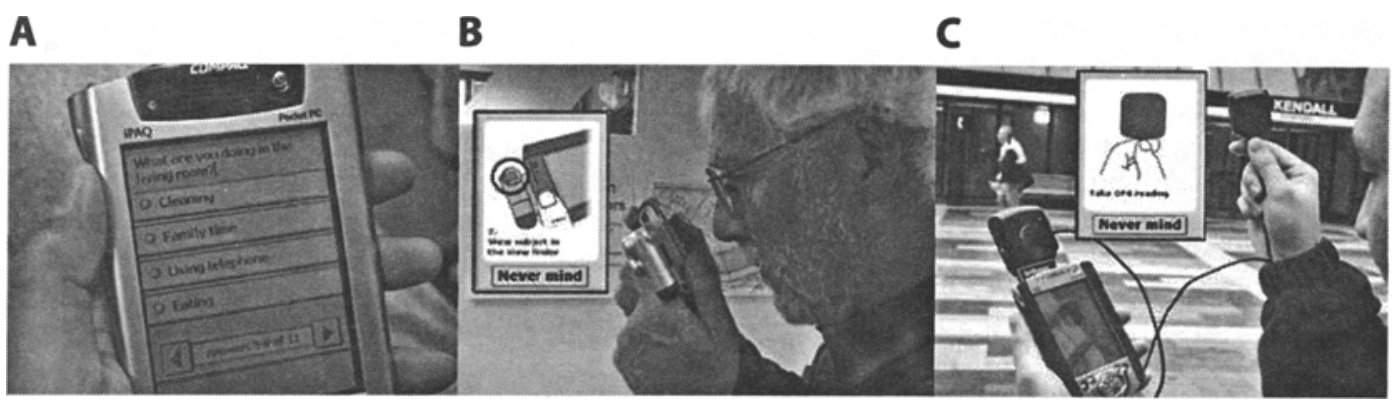

Figure 6. (A) Context-aware ecological momentary assessment protocols are being tested on personal digital assistants running custom MIT software that offers a variety of options for acquiring self-report data from users or subjects in experiments. This image shows one screen from a sampling protocol used in a study to collect training data for algorithms that automatically detect activities in the home setting (B) The software permits the use of data collection sensors, such as cameras, microphones, and a wireless heart rate monitor. This image shows a user taking a picture with the camera plug-in and one of the built-in tutorial screens. (C) The software can also either prompt for sensor data, such as taking a global positioning system (GPS) reading, or use continuously acquired sensor data to trigger a set of self-report questions to be presented. Here, a user is acquiring a GPS sample, which is done by holding up a small antenna plugged into the GPS device. These technologies are bulky, but in less than 10 years, the enabling technology (e.g., GPS) will be standard in mobile phones. From "Technological Innovations Enabling Automatic, Context-Sensitive Ecological Momentary Assessment," by S. S. Intille, 2007. In A. Stone, S. Shiffman, A. Atienza, and L. Nebeling (Eds.), The Science of Real-Time Data Capture: Self-Reports in Health Research, pp. 308-337. Oxford: Oxford University Press. Copyright 2007 by Oxford University Press. Reprinted with permission.

cial costs. For instance, recent estimates suggest that the societal costs in the United States to care for all individuals diagnosed each year over their lifetimes approaches $\$ 35$ billion (Ganz, 2007). ASDs clearly represent an emerging public health problem (Newschaffer \& Curran, 2003).

Characteristics of persons with ASD, including communication (Lord \& Paul, 1997) and socialization problems (Mundy \& Stella, 2000), cognitive deficits (Prior \& Ozonoff, 1998), behavioral inflexibility (Lewis \& Bodfish, 1998), and heightened perceptual sensitivity (Baranek, 2002), may make this population more vulnerable to, and less able to cope with, the effects of stressors than is the general population (Groden, Baron, \& Groden, 2006; Groden, Cautela, Prince, \& Berryman, 1994). Despite a growing appreciation for the role stress plays in the behavior of persons with ASD (see Baron, Lipsitt, \& Goodwin, 2006), little work has been done to develop tools that assess reactions to stressors in this population. Primary reasons for this neglect are likely related to this population's idiosyncratic behavior and inability to provide reliable self-reports about their emotional experience (Hill, Berthoz, \& Frith, 2004). To overcome this problem, researchers are turning to passive telemetric monitors that can unobtrusively and objectively assess physiological responsivity.

For instance, Goodwin et al. (2006) assessed cardiovascular arousal responses to identified environmental stressors in five individuals with ASD and five age- and sex-matched typically developing children. Cardiovascular responses were recorded using the LifeShirt (Vivometrics, Inc.), a noninvasive telemetric recording device that continuously (i.e., beat to beat) stores electrocardiograph (ECG) data on a portable battery-powered electronic recorder worn on the body (for a description, see Wilhelm et al., 2003). Findings revealed individual differences in stress responses within each group and, on average, reduced responsivity to the potential stressors in the individuals with ASD. Results from this research suggested both the types of stressors that can be arousing in persons with ASD and the nature of varying stress responses observed in this population. It also highlights the promise of developing noninvasive, wireless technologies that persons with ASD can wear to monitor physiological stress in real time, thus facilitating more effective ways for these individuals to communicate their arousal states and for educators and caregivers to respond appropriately.

Anxiety disorders. Anxiety disorders represent the most prevalent class of psychiatric disorders in the U.S., afflicting 15.7 million people each year and 30 million people at some point in their lives (Kessler et al., 2005). The economic cost of anxiety disorders is estimated to total $\$ 63.1$ billion to cover psychiatric, nonpsychiatric, and emergency care; hospitalization; prescription drugs; reduced productivity; absenteeism from work; and suicide (Greenberg et al., 1999; Lepine, 2002).

Although anxiety-related disorders clearly represent a major public health concern, there are problems associated with traditional efforts to assess and treat them. First, in order to identify possible triggers of a panic attack, clinicians need detailed information about the situation and the patient's emotional state before and after an attack. In clinical practice, this information is typically obtained by retrospective patient report, which can suffer from a variety of recall bias problems (Rapee, Craske, \& Barlow, 1990). For instance, patients often fail to recall any discrete triggers, or they either over- or underestimate the intensity of the physical symptoms associated with an attack (Margraf, Taylor, Ehlers, Roth, \& Agras, 1987). Second, although laboratory assessments provide control over stimulation, they are not typical of a person's ordinary life, making it difficult to reproduce common situations associated with panic attacks, social phobia, and specific phobias. Third, the laboratory environment is novel and can increase arousal levels in patients with anxiety disorders, making basal rates of emotional and physiological 
responsivity measured in that setting artificially high and underrepresentative (Wilhelm, Alpers, Meuret, \& Roth, 2001). Finally, the laboratory window of observation is limited in time, making infrequent events, such as panic attacks, easy to miss (Wilhelm et al., 2003).

A growing number of clinical researchers aware of these assessment shortcomings are turning to telemetric devices to overcome them. For instance, noninvasive ambulatory monitors that record respiratory, cardiovascular, and electrodermal activity are being used to clarify subjective reports by recording physiological reactions related to anxiety when and where they happen (Hofmann, 1999; Wilhelm et al., 2003).

Adherence and compliance monitoring. The full benefit of any effective treatment can be achieved only if prescribed treatment regimens are followed. Unfortunately, average adherence rates as low as $43 \%$ are commonly found in patients receiving treatment for chronic conditions (Claxton, Cramer, \& Pierce, 2001). Poor adherence to prescribed treatment contributes to substantial worsening of morbidity, mortality, and increased health care costs in the United States. For instance, $33 \%-69 \%$ of all medication-related hospital admissions in the United States are a result of poor medication adherence, costing society approximately $\$ 100$ billion a year (Berg, Dischler, Wagner, Raia, \& Palmer-Shevlin, 1993; McDonnell \& Jacobs, 2002). Although adherence to treatment regimens is clearly important, physicians' abilities to recognize and intervene on occasions of nonadherence are poor. The use of telemetrics and two-way communication devices are enhancing these efforts.

Medication adherence has traditionally been estimated by counting returned unused medications (pill counts), by interviewing patients, or by having patients complete diaries and questionnaires. All of these methods are strongly biased toward overestimation of adherence, due to social pressure for the patient to appear compliant to the physician (Cramer, Mattson, Prevey, Scheyer, \& Ouellette, 1989; Elixhauser, Eisen, Romeis, \& Homan, 1990). For instance, "pill dumping," "parking lot compliance," and "white coat compliance" are frequently reported in experimental adherence studies (Rudd et al., 1989; Urquhart, 1994). Although directly observing adherence is a more accurate sampling strategy, this method is often expensive and burdensome for the healthcare provider (Osterberg \& Blaschke, 2005). To overcome these obstacles, researchers are turning to memory-equipped telemetric devices to wirelessly and automatically capture adherence data. These devices are capable of recording and stamping the time of opening bottles, dispensing drops (e.g., in treating glaucoma), or discharging a canister (e.g., in treating asthma) (Urquhart \& De Klerk, 1998).

For instance, Aloia et al. (in press) assessed adherence to treatment in 71 patients with obstructive sleep apnea. Participants were supplied with an in-home telemetric treatment device that delivered positive airway pressure during sleep. These passive devices were equipped with objective monitors that stored nightly use data over a full year on a small plastic card housed within the device. The number of minutes that the machine was in operation at the prescribed pressure was recorded. This reflected the time that the machine was used and served as the dependent variable of adherence. Par- ticipants' adherence data were continuously collected during treatment and were downloaded at 3-, 6-, and 12-month follow-up visits without the participants' knowledge. Time series analysis was used to determine use patterns over the first 365 days of treatment for each participant. The data suggested seven distinct use patterns, providing a greater understanding of adherence behavior and suggesting time points at which individuals develop adherent or nonadherent behavior that may guide future adherence interventions.

Telemetric devices may also be useful in improving adherence. For instance, cognitive-behavioral approaches have resulted in more than $90 \%$ of patients with HIV achieving $95 \%$ adherence to antiretroviral medications (Safren et al., 2001; Tuldrà et al., 2000). However, such interventions require considerable resources, and adherence is rarely sustained after the intervention is withdrawn. Researchers are turning to telemetric devices, such as mobile phones, PDAs, two-way pagers, and medication vials equipped with alarms, to enhance social and emotional support for adherent behavior. For example, Fishkin and Wang (2003) have developed a portable monitoring pad which combines RFID tags with a sensitive scale to detect when people pick up and put down pill bottles and to measure how their weight has changed. Coupled with a wireless, network-enabled tablet display, the system can proactively remind the user and people in his or her social or caregiver network which pills to take, how many, and when.

Medical monitoring. According to data from the United Nations Population Division (2001), approximately 606 million people in the world were over 60 in the year 2000; by 2050, this percentage is expected to double to two billion people. Current healthcare systems dominated by expensive and infrequent patient visits to physician offices cannot adequately service the growing needs of the aging population. Coupled with the finding that quality of life for people in their homes is generally better than for those in institutions (Rivlin \& Wiener, 1988) and the high cost for institutional care, relative to home care, medical providers are turning to proactive, telemetric health care technologies to provide better monitoring and feedback for detecting and correcting health problems when they first appear in the home environment (for a review, see Pentland, 2005).

Combining multivariate sensor streams with pattern recognition and machine-learning techniques, these systems can continuously record a user's vital signs, motor activity, social interactions, sleep patterns, and other health indicators to monitor well-being, trigger reminders, and broadcast relevant information to caregivers. For instance, the LiveNet system created at the Massachusetts Institute of Technology (MIT) Media Laboratory combines a customizable PDA-based wearable platform, a software and network resource discovery application program, and a real-time machine-learning inference infrastructure to gather a variety of sensor data, perform real-time processing and mining on these data, return classification results and statistics, trigger alarms, and enable peer-to-peer wireless networking. Sung, Marci, and Pentland (2005) have highlighted the benefits of using telemetric technology for medical monitoring and have reviewed the many promising applications of these devices. First, such power- 
ful diagnostic sensing technologies can enable doctors to obtain more context-specific information directly, instead of relying on a patient's recollection of past events and symptoms, which tend to be vague, incomplete, and error prone. Second, unlike infrequent surveys and interviews, continuous monitoring can enable a very fine granularity of quantitative data to be obtained. Third, wireless monitoring of behavior in the natural environment can ensure capture of relevant events and concomitant physiology wherever the patient is, expanding the view of health care beyond the traditional outpatient and inpatient settings. A few of the potential applications they suggest are (1) monitoring the movement states of Parkinson's patients to establish a timeline of symptom severity and motor complications, (2) characterizing and identifying epileptic seizures through accelerometry to develop an ambulatory monitor with a real-time seizure classifier, (3) monitoring physiological and behavioral reactions to tailor medications to an individual, and (4) developing physiological and behavioral measures to classify emotional states associated with preclinical symptoms of psychosis, mood, anxiety, and personality disorders.

Motivating healthy behavior. Chronic conditions, such as heart disease and cancer, are the leading causes of morbidity and mortality in the United States, accounting for over half of all deaths in this country (Centers for Disease Control and Prevention, 2006). Although medical interventions can help reduce chronic diseases, practicing healthy behaviors, such as eating a healthy diet, getting regular exercise, and avoiding alcohol and tobacco use, can prevent them (Centers for Disease Control and Prevention, 1989, 2001, 2002; National Institute on Alcohol Abuse and Alcoholism, 2000; National Institutes of Health, 1998). However, in order to motivate healthy behavior, information must be tailored to an individual and delivered when he or she is most receptive (Fogg, 1999). Context-aware mobile computing devices that use mobile phones, PDAs, and wrist watches capable of automatically inferring what a person is doing from wearable or ubiquitous sensors are being used to provide instantaneous and personalized feedback when and where a person needs it (see Intille, 2004). For instance, researchers have customized mobile phones with text messaging to deliver individually tailored messages for patients as they interact with their natural environments (S. Bauer, Percevic, Okon, Meermann, \& Kordy, 2003; Franklin, Waller, Pagliari, \& Greene, 2003). Standard PDAs with integrated barcode scanners can allow users to scan multiple items in a grocery store, obtain relative comparisons of nutritional values, and receive tailored, motivational information about a healthy diet at key points in the decision-making process (i.e., when purchasing food; Intille, Kukla, Farzanfar, \& Bakr, 2003). Mobile, computerized games are also being developed to encourage healthy behaviors. For instance, Pentland (2005) has created a computer game for young diabetics, using a belt-worn motion sensor, a wireless Internet connection, and a standard PDA to motivate children to record and, later, guess their food intake, activity, and blood sugar level as recorded by wearable sensors.

\section{ISSUES WITH TELEMETRICS AND FUTURE DIRECTIONS}

Although telemetrics clearly confer significant advantages for measuring and intervening on a wide variety of behaviors in natural settings, one must acknowledge special issues relating to privacy and confidentiality, practical considerations, and statistical and measurement challenges when this technology is used. This section will briefly review these issues and will highlight areas that require future research.

\section{Privacy and Confidentiality}

Although telemetrics can make it easier to sense, understand, and react to phenomena in the physical world, these technologies carry with them potential dangers that must be appropriately anticipated (see Albrecht \& McIntyre, 2005). For instance, assurances must be made that data will not be gathered to spy on others without any controlling authority or used to jeopardize services to which a research participant is otherwise entitled (e.g., insurance coverage when a heart rate monitor shows arrhythmia). Computer scientists who are manufacturing and advocating the use of telemetric technologies are among the first to acknowledge these potential problems and are taking steps to ensure security and privacy. Security is being addressed through data encryption programs and system designs with clear indicators that recording is occurring, allowing those being sensed or recorded to determine when and where data are gathered and how they are distributed (Abowd \& Mynatt, 2000; Iachello \& Abowd, 2005; Intille, 2007; Intille \& Intille, 2003; Starner, 2001).

Behavior scientists who use this technology must also play an active role in ensuring that research participants understand what data are being collected, what the data could be used to infer, and how one can stop data collection at desired times. Such investigator responsibilities can be revisited in the American Psychological Association's Ethical Principles of Psychologists and Code of Conduct (American Psychological Association, 2002). Discussions of the limits of confidentiality, including the foreseeable use of information generated through psychological activities, should occur at the outset of a study and, thereafter, as new circumstances warrant. Behavioral scientists should also inform participants of the risks to privacy and limits of confidentiality and, before recording voices, images, or other types of data telemetrically, should obtain explicit consent from all such persons or their legal representatives. To minimize intrusions on privacy, behavioral scientists need to include in written and oral reports only information germane to the purposes for which the recordings are made and discuss confidential information obtained in their work only for appropriate scientific or professional purposes. Behavioral scientists must also be careful not to disclose information that could reasonably lead to the identification of a research participant, unless they have obtained prior consent from the person observed. As telemetric technologies become more pervasive, investigators and research participants will have to compare the perceived benefits and costs of the uses of telemetrics. In the interim, attention to issues of security, visibility, control, and privacy should help ensure a more positive use of these technologies. 


\section{Practical Considerations When Telemetrics Are Used to Assess Behavior}

In addition to privacy and confidentiality concerns, there are a number of practical issues that need to be considered when telemetrics are used to assess behavior. For instance, one must consider the financial costs involved in purchasing emerging technologies. Fortunately, as telemetric devices increase in their capabilities, their size and cost decrease. Intel predicts that Moore's Law (Moore, 1965) - a doubling of computational power and speed every 24 months-will continue for at least the next 10 years. Combined with lowering costs and increasing capabilities of memory, ${ }^{2}$ the functionality-to-price ratio of telemetric devices will only continue to improve. In the next decade, mobile devices, such as mobile phones and PDAs, will have the computational, memory, and networking capabilities of today's desktop computers. Behavioral scientists interested in telemetric monitoring will be able to leverage these common devices, since they will have already been purchased by people for their communication, entertainment, and health care needs (Intille, 2007; Intille, Larson, \& Kukla, 2002).

Investigators interested in using telemetrics in their professional practice must also be able to identify and learn how to use this technology in a manner that meets acceptable standards for practice. At the time of this writing, peer review journals devoted specifically to technological developments and applications in the behavioral sciences include Behavioral Assessment, Behavior Research Methods (formerly Behavior Research Methods, Instruments, \& Computers), Social Science Computer Review, and Computers in Human Behavior. Annual conferences highlighting these technologies and demonstrating their capabilities through exhibition displays include Measuring Behavior, the International Conference on Methods and Techniques in Behavior Research; the Association for Computing Machinery (ACM) Special Interest Group on Computer-Human Interaction (SIGCHI); and the Institute of Electrical and Electronics Engineers (IEEE) Computer Society. Computer science departments in academia have also begun to sponsor events to showcase telemetric technologies. For instance, a 3-day international workshop on wearable and implantable body sensor networks was recently hosted by the MIT Media Lab.

After identifying a useful system for telemetric recording and before initiating a study, researchers should get better acquainted with their equipment by using the technology themselves for at least several days prior to actual data collection. This allows investigators to experience firsthand unforeseeable difficulties that a participant may encounter and to make necessary adjustments to the assessment procedure. Interacting with the technology can also help researchers better train their participants and promote compliance while under observation.

\section{Statistical and Measurement Issues}

Telemetrics capable of making assessments repeatedly in multiple environments will produce intensive longitudinal data (Walls \& Schafer, 2006), a new class of multivariate, multiple-subject databases that include many more time points than are typically found in the behavioral sciences (e.g., 200 or more recorded occasions per person).
Such intensive data will undoubtedly provide more power to ask and answer a range of questions relating to a given behavior's temporal features and context dependency. However, along with these opportunities come special statistical and measurement challenges that must be effectively dealt with. Key issues include the consideration of time as a variable, the anticipation and handling of measurement errors in data streams, the selection of appropriate statistical techniques for modeling intensive longitudinal data both within and across persons, and the potential for behavioral reactivity to telemetric measurement.

Given the sampling intensity of telemetrics, establishing the appropriate time scale for a study (e.g., hourly, daily, or weekly), the sampling rate (i.e., spacing of measurement), and which time-varying and time-invariant covariates should be included for detecting states or changes in a given behavior will need to be determined prior to large-scale implementation (for a more extended review of these issues, see Walls, Höppner, \& Goodwin, 2007). Variations in response times within and between subjects and the presence of missing data must be accurately modeled to produce meaningful results. In most instances, telemetrics will record intensively and, thus, generate very dense data streams that reduce the chances of irregular or missing data. However, longer gaps of missing data may be present if signals fall below a minimum detection level or are not received at all. These errors may arise as a result of user errors, calibration problems, sensor misplacement, and/or wireless data transfer (for a more thorough review of missing data and telemetrics, see Nusser et al., 2006). Since many of these data characteristics may not be known a priori, more extended exploratory data collection procedures and changing study designs may be needed before moving on to confirmatory data analyses.

Repeated measurements over time on a single subject create serial dependency that violates the statistical assumption that errors in the data are independent across observations. Analytical approaches that can calculate an autocorrelation between adjacent observations will be needed to transform serially dependent data to be independent before any further analyses can be carried out. There is a growing number of statistical methods that are capable of handling the vast number of observations and dependency inherent in intensive longitudinal data and that can model within- and between-person observations simultaneously (for extended reviews of these methods, see Singer \& Willett, 2003; Walls et al., 2007; Walls \& Schafer, 2006). Some especially promising approaches include time series analysis, multilevel modeling, survival analysis and point process modeling, and pattern-based methods, such as cluster analysis and growth mixture models. Time series analysis (Box \& Jenkins, 1976; Chatfield, 1996; Glass, Wilson, \& Gottman, 1975; Peña, Tiao, \& Tsay, 2001; Velicer \& Fava, 2003) can be used to uncover the autoregressive structure of data, examine temporal regularities (i.e., lawfulness) or response variations over time, and assess the effects of either a planned or an unplanned intervention. Techniques capable of visually displaying, quantifying, and analyzing two or more synchronized time series at either the variable level (e.g., heart rate and motor movement) or the person level (e.g., mother and child interaction) are also emerging 
(Höppner, Goodwin, Velicer, \& Heltshe, in press; Lamey, Hollenstein, Lewis, \& Granic, 2004). Multilevel models or hierarchical linear models that conceptualize interindividual heterogeneity in intraindividual change as variability around a common trajectory are useful if one wishes to simultaneously examine and explain heterogeneity in data sets containing both within- and across-person observations. Survival analysis (Kalbfleisch \& Prentice, 2002; Lawless, 2002; Lee \& Wang, 2003) and point process modeling (Blossfeld \& Rohwer, 2002; Diggle, 1998; Lindsey, 1999) can be used to characterize the distribution of timeto-event data, determine the likelihood of an event's occurring, test for differences between groups of individuals, and model the influences covariates have on duration data. Lastly, if the existence of subgroups is hypothesized but not known a priori, pattern-based methods, such as cluster analysis and growth mixture models, may be used to classify individuals into more homogenous groups on the basis of similar or dissimilar trajectories (for a review of common pattern-based methods, see D. J. Bauer \& Curran, 2003; Bergman \& Magnusson, 1997; Dumenci \& Windle, 2001; Muthén, 2001; Nagin, 1999).

Finally, although designers of telemetric technology are working to decrease user burden and annoyance (Bodine \& Gemperle, 2003; Ho \& Intille, 2005; Hudson et al., 2003; Kern \& Schiele, 2003) and to construct device forms that are discreet and comfortable enough to wear or carry for long periods of time (Gemperle, Kasabach, Stivoric, Bauer, \& Martin, 1998; Knight, Baber, Schwirtz, \& Bristow, 2002), their potential for causing measurement reactivity is currently unknown. In many cases, measurement reactivity will be difficult to assess until participants have engaged in data collection for an extended period of time. Behavioral scientists should be aware of this potential artifact and should take proactive steps to identify and minimize it. Some suggested ways to assess reactivity to telemetric measurement include piloting the data collection devices with participants before initiating a study, interviewing participants about their experience with the technology during and after a study, and conducting preliminary analyses to look for systematic changes in obtained data (e.g., diminished within-person variation over time).

\section{SUMMARY AND CONCLUSIONS}

This review has described a new class of wireless measurement technology called telemetrics that have the potential to facilitate repeated assessments, reduce behavioral reactivity to measurement, and enhance ecological validity in behavioral science research. Passive (e.g., wearable and ubicomp) and active (e.g., mobile phones and PDAs) telemetric technology can enable behavioral scientists to measure behavioral, cognitive, affective, and physiological processes in real time in natural settings, making intensive longitudinal studies that appreciate contextual and temporal patterns of human behavior feasible. Applied examples of telemetrics illustrated how this technology can gather data that a person is unable to communicate (e.g., heart rate and autism), be deployed in natural environments to corroborate self-reports (e.g., anxiety disorders and adher- ence behavior), enable real-time monitoring (e.g., in-home medical monitoring), and provide individualized, just-intime feedback based on an individual's behavioral response (e.g., motivating healthy behavior).

Although telemetrics may be a useful addition to the behavioral scientist's armamentarium, a scientific approach to behavioral assessment permits a diverse set of methods. Telemetrics should be used only if they can sample behavior in a way that best suits the research question and aims of a study. Like other methods and measures for assessing behavior, telemetrics have both strengths and weaknesses; they are not a panacea. For instance, wearable computers that place sensors on the body can raise problems if people fail to maintain and wear the equipment correctly or have a difficult time habituating to the sensors. Ubicomp sensing is potentially limited by its inability to gather some types of data from a distance (e.g., physiological responsivity), the high cost associated with large scale implementation, and the fact that the technology is effective only where the sensing infrastructure exists. Active telemetrics can raise problems since they exclude a large percentage of the population with mental and physical handicaps who do not have the requisite cognitive and/or fine motor abilities needed to attend to and enter data on a PDA or another handheld device (Wilson et al., 1992). In addition, some occupations (e.g., teacher, doctor, or policeman) and activities (e.g., attending church, driving, or conversing with another person) may prevent respondents from entering data on many occasions (Scollon, Kim-Prieto, \& Diener, 2003). Prompting people multiple times a day can also "disrupt the ecology of daily experience" and cause irritation that influences reports (Korotitsch \& Nelson-Gray, 1999; Silvia, 2002; Tennen, Suls, \& Affleck, 1991).

Perhaps the best approach to sampling behavior is to collect data using multiple methods (e.g., physiological, selfreport, direct observation) and assess convergence between them. Such multimethod assessments would use alternative measures that differ in method factors but assess some facet of the target behavior. For instance, an integrative assessment protocol could include wearable sensors to record physiological data, a mobile phone or PDA to record subjective information such as feelings and opinions, and environmental sensors to obtain data on behavior and context (e.g., location, proximity, or activity). Naturally, the configuration of such a system would be dictated by an investigator's chosen experimental design, dependent and independent variables, population studied, and mode of treatment.

This review also highlighted special issues relating to privacy and confidentiality, practical considerations, and statistical and measurement challenges when telemetrics are used. As a special area of expertise, telemetrics is developing rapidly, and these issues will undoubtedly continue to present challenges and opportunities for the.study of human behavior. For instance, in addition to using the aforementioned statistical methods to model intensive longitudinal data generated by telemetrics, there is a strong possibility that further methodological innovations will arise as a result of adapting these techniques to answer more complex temporal and contextual psychological questions (Walls \& Schafer, 2006). 
Finally, much of the literature on telemetrics consists of proof of concept demonstrations designed to show what can be done with this technology. To date, many of these applications lack empirical evaluation. The quality of telemetric applications could be strengthened by collaborative efforts between developers of this technology and behavioral scientists during the planning stages. Behavioral scientists are also encouraged to become involved by providing sites where prototypes of the technology can be field-tested and data on reliability and validity gathered. Such collaborative arrangements would facilitate the evaluation of telemetrics, help determine their functionality and utility, and provide a method for increasing behavioral scientists' involvement in this technology.

\section{AUTHOR NOTE}

This work was partially supported by Grant 1290 from Autism Speaks. An earlier version of the article was presented at the annual meeting of the American Psychological Association and the Society for Behavioral Medicine. The authors thank Lewis Lipsitt, Ted Walls, and Kathleen Gorman for providing helpful comments on previous drafts of the manuscript. We are also grateful to Meredith Phelps for assisting with manuscript preparation. Correspondence concerning this article and reprint requests should be sent to M. S. Goodwin, Associate Director of Research, The Groden Center, Inc., 86 Mt. Hope Ave., Providence, RI 02906 (e-mail: msgoodwin@earthlink.net).

\section{REFERENCES}

ABOWD, G. D., ATKeson, C. G., Bobick, A., Essa, I. A., MAcInTYre, B., MYNATT, E., \& STAMER, T. E. (2000). Living laboratories: The future computing environments group at the Georgia Institute of Technology. In G. Szwillus \& T. Turner (Eds.), CHI '00: Extended abstracts on human factors in computing systems (pp. 215-216). New York: ACM Press.

ABOWD, G. D., \& MYNATT, E. (2000). Charting past, present, and future research in ubiquitous computing. ACM Transactions on ComputerHuman Interaction, 7, 29-58.

ALBRECHT, K., \& MCINTYRE, L. (2005). Spychips: How major corporations and government plan to track your every move with RFID. Nashville, TN: Nelson Current.

ALLPORT, G. W. (1961). Pattern and growth in personality. New York: Holt, Rinehart \& Winston.

ALLPORT, G. W. (1962). The general and the unique in psychological science. Journal of Personality, 30, 405-422.

Alota, M. S., Goodwin, M. S., Velicer, W. F., Arnedt, J. T., ZiMMERMAN, M., ET AL. (in press). Time series analysis of treatment adherence patterns in individuals with obstructive sleep apnea: A brief report. Annals of Behavioral Medicine.

AMERICAN PSYCHIATRIC Association (1994). Diagnostic and statistical manual of mental disorders (4th ed.). Washington, DC: Author.

American Psychological Association (2002). Ethical principles of psychologists and code of conduct. Washington, DC: Author.

Asada, H. H., Shaltis, P., Reisner, A., Rhee, S., \& Hutchinson, R. C. (2003). Mobile monitoring with wearable photoplethysmographic biosensors. IEEE Engineering in Medicine \& Biology Magazine, 22, 28-40.

AsHBrooK, D., \& STARNER, T. (2003). Using GPS to learn significant locations and predict movement across multiple users. Personal Ubiquitous Computing, 7, 275-286.

BALTES, P. B., REESE, H. W., \& LIPSITT, L. P. (1980). Life-span developmental psychology. Annual Review of Psychology, 31, 65-110.

Baltes, P. B., ReEse, H. W., \& Nesselroade, J. R. (1988). Life-span developmental psychology: Introduction to reseanch methods. Hillsdale, NJ: Erlbaum.

BAO, L., \& INTILLE, S. S. (2004). Activity recognition from user-annotated acceleration data. In A. Ferscha \& F. Mattern (Eds.), Proceedings of PERVASIVE 2004 (Vol. LNCS 3001, pp. 1-17). Berlin: Springer.

BARANEK, G. T. (2002). Efficacy of sensory and motor interventions for children with autism. Joumal of Autism \& Developmental Disonders, 32, 397-422.

Barlow, D. H., \& Hersen, M. (1984). Single case experimental designs: Strategies for studying behavior change (2nd ed.). New York: Allyn \& Bacon.

BaroN, M. G., LIPSITT, L. P., \& Goodwin, M. S. (2006). Scientific foundations for research and practice. In M. G. Baron, J. Groden, G. Groden, \& L. P. Lipsitt (Eds.), Stress and coping in autism (pp. 42-68). Oxford: Oxford University Press.

BARRETT, L. F., \& BARRETT, D. J. (2001). An introduction to computerized experience sampling in psychology. Social Science Computer Review, 19, 175-185.

BAUER, D. J., \& CURRaN, P. J. (2003). Distributional assumptions of growth mixture models: Implications for overextraction of latent trajectory classes. Psychological Methods, 8, 338-363.

Bauer, S., Percevic, R., Okon, E., Meermann, R., \& Kordy, H. (2003). Use of text messaging in the aftercare of patients with bulimia nervosa. European Eating Disorders Review, 11, 279-290.

Berg, J. S., Dischler, J., Wagner, D. J., Raia, J. J., \& PalmerShevLIN, N. (1993). Medication compliance: A healthcare problem. Annals of Pharmacotherapy, 27(Suppl. 9), S1-S24.

Bergman, L. R., \& MAGNusson, D. (1997). A person-oriented approach in research on developmental psychopathology. Development \& Psychopathology, 9, 291-319.

BLOSSFELD, H. P., \& ROHWER, G. (2002). Techniques of event history modeling: New approaches to causal analysis (2nd ed.). Mahwah, NJ: Erlbaum.

BoDINE, K., \& GEMPERLE, F. (2003). Effects of functionality on perceived comfort of wearables. In Proceedings of the Seventh IEEE International Symposium on Wearable Computers (pp. 57-61). Los Alamitos, CA: IEEE Computer Society Press.

Bolger, N., DAvis, A., \& RAFAeti, E. (2003). Diary methods: Capturing life as it is lived. Annual Review of Psychology, 54, 579-616.

Box, G. E. P., \& Jenkins, G. M. (1976). Time series analysis, forecasting, and control. San Francisco: Holden-Day.

BRONFENBRENNER, U. (1977). Toward an experimental ecology of human development. American Psychologist, 32, 513-531.

BRONFENBRENNER, U. (1979). The ecology of human development: Experiments by nature and design. Cambridge, MA: Harvard University Press.

Broverman, D. M. (1962). Normative and ipsative measurement in psychology. Psychological Review, 4, 295-305.

BRUNSWIK, E. (1947). Systematic and representative design of psychological experiments, with results in physical and social perception. Berkeley: University of California Press.

BURKE, M. J., \& Normand, J. (1987). Computerized psychological testing: Overview and critique. Professional Psychology: Research \& Practice, 18, 42-51.

BuRNeTt, K. F., TAYLOR, C. B., \& AGRAS, W. S. (1985). Ambulatory computer-assisted therapy for obesity: A new frontier for behavior therapy. Journal of Consulting \& Clinical Psychology, 53, 698-703.

CAMpbell, D. T., \& Stanley, J. C. (1966). Experimental and quasiexperimental designs for research. Chicago: Rand McNally.

Centers for Disease Control and Prevention (1989). Reducing the health consequences of smoking: 25 years of progress; a report of the Surgeon General (Pub. 89-8411). Rockville, MD: U.S. Department of Health and Human Services, CDC, Office on Smoking and Health.

Centers for Disease Control and Prevention (2001). Increasing physical activity: A report on recommendations of the Task Force on Community Prevention Services. Morbidity \& Mortality Weekly Report, 50(No. RR-18), 1-14.

Centers for Disease Control and Prevention (2002). Surveillance for asthma - United States, 1980-1999. Morbidity \& Mortality Weekly Report, 51(No. SS-1), 1-13.

Centers for Disease Control and Prevention (2006). Deaths: Final data for 2003. National Vital Statistics Reports, 54, 1-15.

CHATFirLd, C. (1996). The analysis of time series: An introduction (6th ed.). Boca Raton, FL: CRC Press.

Claxton, A. J., Cramer, J., \& Pierce, C. (2001). A systematic review of the associations between dose regimens and medication compliance. Clinical Therapeutics, 23, 1296-1310.

CONE, J. D. (1986). Idiographic, nomothetic, and related perspectives in behavioral assessment. In R. O. Nelson \& S. C. Hayes (Eds.), Concep- 
tual foundations of behavioral assessment (pp. 111-128). New York: Guilford.

Conner, T., Barrett, L. F., Bliss-Moreau, E., Lebo, K., \& Kaschub, C. (2003). A practical guide to experience-sampling procedures. Journal of Happiness Studies, 4, 53-78.

Conner, T., Barrett, L. F., Tugade, M. M., \& Tennen, H. (2007). Personality in context: The theory and practice of experience sampling. In R. W. Robins, R. C. Fraley, \& R. Kreuger (Eds.), Handbook of research methods in personality psychology (pp. 190-192). New York: Guilford.

CooK, T. D., \& CAMPBell, D. T. (1979). Quasi-experimentation. Chicago: Rand-McNally.

Cramer, J. A., Mattson, R. H., Prevey, M. L., Scheyer, R. D., \& OUELLETTE, V. L. (1989). How often is medication taken as prescribed? A novel assessment technique. Journal of the American Medical Association, 261, 3273-3277.

CronBaCH, L. J. (1946). Response sets and test validity. Educational \& Psychological Measurement, 6, 475-494.

DANZIGER, K. (1990). Constructing the subject: Historical origins of psychological research. Cambridge: Cambridge University Press.

Dickie, C., Vertegaal, R., Shell, J. S., Sohn, C., Cheng, D., \& AouDEH, O. (2004). Eye contact sensing glasses for attention-sensitive wearable video blogging. In Proceedings of the Conference on Human Factors in Computing Systems: Extended abstracts (pp. 769-770). New York: ACM Press.

DiGGLE, P. J. (1998). An approach to the analysis of repeated measurements. Biometrics, 44, 959-971.

DUMENCI, L., \& WiNDLE, M. (2001). Cluster analysis as a method of recovering types of intraindividual growth trajectories: A Monte Carlo study. Multivariate Behavioral Research, 36, 501-522.

Elixhauser, A., Eisen, S. A., Romeis, J. C., \& Homan, S. M. (1990). The effect of monitoring and feedback on compliance. Medical Care, 28, 882-893.

EPSTEIN, S. (1983). Aggregation and beyond: Some basic issues on the prediction of behavior. Journal of Personality, 51, 360-392.

ERDMaN, H. P., KleIN, M. H., \& Greist, J. H. (1985). Direct patient computer interviewing. Journal of Consulting \& Clinical Psychology, $53,760-773$.

FARRELL, A. D. (1991). Computers and behavioral assessment: Current applications, future possibilities, and obstacles to routine use. Behavioral Assessment, 13, 159-179.

Fistukin, K. P., JiANG, B., Philipose, M., \& Roy, S. (2004). I sense a disturbance in the force: Unobtrusive detection of interactions with RFID-tagged objects. In N. Davies \& I. Sito (Eds.), 6th International Conference on Ubiquitous Computing (Ubicomp 2004) (pp. 268-282). Berlin: Springer.

FISHKIN, K. P., \& WANG, M. (2003). A flexible, low-overhead ubiquitous system for medication monitoring (Intel Research Seattle Tech. Rep. No. IRS-TR-03-011). Seattle: Intel.

FoGG, B. J. (1999). Persuasive technologies. Communications of the $A C M, 42,27-29$.

FOMBONNE, E. (2003). The prevalence of autism. Journal of the American Medical Association, 289, 87-89.

Frankin, V., Waller, A., Pagliari, C., \& Greene, S. (2003). "Sweet Talk": Text messaging support for intensive insulin therapy for young people with diabetes. Diabetes Technology \& Therapeutics, 5, 991-996.

GANZ, M. L. (2007). The lifetime distribution of the incremental societal costs of autism. Archives of Pediatrics \& Adolescent Medicine, 161, 343-349.

Gemmell, J., Bell, G., Lueder, R., Drucker, S., \& Wong, C. (2002). MyLifeBits: Fulfilling the Memex vision. In Proceedings of $A C M$ Multimedia '02 (pp. 235-238). New York: ACM Press.

Gemperle, F., Kasabach, C., Stivoric, J., Bauer, M., \& Martin, R. (1998). Design for wearability. In The Second International Symposium on Wearable Computers (pp. 116-122). Los Alamitos, CA: IEEE Computer Society.

Glass, G. V., Wilson, V. L., \& Gotrman, J. M. (1975). Design and analysis of time series experiments. Boulder: Colorado Associate University Press.

Goodwin, M. S., Groden, J., Velicer, W. F., LiPsitT, L. P., Baron, M. G., HofmanN, S. G., \& Groden, G. (2006). Cardiovascular arousal in individuals with autism. Focus on Autism \& Other Developmental Disabilities, 21, 100-123.
Greenberg, P. E., Sisitsky, T., Kessler, R. C., Finkelstein, S. N., BERNDT, E. R., DAVIDSON, J. R., ET AL. (1999). The economic burden of anxiety disorders in the 1990s. Journal of Clinical Psychiatry, 60, 427-435.

Groden, J., BARON, M. G., \& Groden, G. (2006). Assessment and coping strategies. In M. G. Baron, J. Groden, G. Groden, \& L. P. Lipsitt (Eds.), Stress and coping in autism (pp. 15-41). Oxford: Oxford University Press.

Groden, J., Cautela, J., Prince, S., \& Berryman, J. (1994). The impact of stress and anxiety on individuals with autism and developmental disabilities. In E. Schopler \& G. Mesibov (Eds.), Behavioral issues in autism (pp. 178-190). New York: Plenum.

HARPER, R. G., \& WIENS, A. N. (1979). Nonverbal behaviors as unobtrusive measures. In L. Sechrest (Eds.), Unobtrusive measurement today: New directions for methodology of behavioral science (pp. 59-73). San Francisco: Jossey-Bass.

HARRIS, F. C., \& LAHEY, B. B. (1982). Subject reactivity in direct observational assessment: A review and critical analysis. Clinical Psychology Review, 2, 523-538.

HAYNES, S. N., \& HORN, W. F. (1982). Reactivity in behavioral observation: A review. Behavioral Assessment, 4, 369-385.

HEALEY, J. (2000). Future possibilities in electronic monitoring of physical activity. Research Quarterly for Exercise \& Sport, 71, 137-145.

HILL, E., BerTHOZ, S., \& FRITH, U. (2004). Brief report: Cognitive processing of own emotions in individuals with autistic spectrum disorder and in their relatives. Journal of Autism \& Developmental Disorders, 34, 229-235.

Ho, J., \& INTILLE, S. S. (2005). Using context-aware computing to reduce the perceived burden of interruptions from mobile devices (House_n tech. rep.). Cambridge, MA: Massachusetts Institute of Technology, Department of Architecture.

HofmanN, S. G. (1999). The value of psychophysiological data for cognitive behavioral treatment of panic disorder. Cognitive \& Behavioral Practice, 6, 244-248.

HÖPPNER, B. B., GOODWIN, M. S., Velicer, W. F., \& Heltshe, J. (in press). An applied example of pooled time series analysis: Cardiovascular reactivity to stressors in children with autism. Multivariate Behavioral Research.

Hudson, S. E., Fogarty, J., Atkeson, C. G., Avrahami, D., Forlizzi, J., KIESLER, S., ET AL. (2003). Predicting human interruptability with sensors: A Wizard of $\mathrm{Oz}$ feasibility study. In Proceedings of the Conference on Human Factors and Computing (pp. 257-264). New York: ACM Press.

IACHELLO, G., \& ABOWD, G. D. (2005). Privacy and proportionality: Adapting legal evaluation techniques to inform design in ubiquitous computing. In Proceedings of the Conference on Human Factors in Computing Systems (pp. 91-100). New York: ACM Press.

INTILLE, S. S. (2002). Designing a home of the future. IEEE Pervasive Computing, 1, 76-82.

INTILLE, S. S. (2004). A new research challenge: Persuasive technology to motivate healthy aging. Transactions on Information Technology in Biomedicine, 8, 235-237.

INTILLE, S. S. (2007). Technological innovations enabling automatic, context-sensitive ecological momentary assessment. In A. Stone, S. Shiffman, A. Atienza, \& L. Nebeling (Eds.), The science of realtime data capture: Self-reports in health research. (pp. 308-337). Oxford: Oxford University Press.

INTILLE, S. S., \& INTILLE, A. M. (2003). New challenges for privacy law: Wearable computers that create electronic digital diaries (Technical rep.). Cambridge, MA: Massachusetts Institute of Technology.

INTLLE, S. S., KUKI A, C., FARZANFAR, R., \& BAKR, W. (2003). Just-in-time technology to encourage incremental, dietary behavior change. In Proceedings of the AMLA 2003 Symposium (pp. 719-723). New York: Wiley.

Intille, S. S., Larson, K., Beaudin, J. S., NAWYN, J., TAPIA, E. M., \& KAUSHIK, P. (2005). A living laboratory for the design and evaluation of ubiquitous computing technologies. In CHI 'OS: Extended abstracts on human factors in computing systems (pp. 1941-1944). New York: ACM Press.

INTILLE, S. S., LARSON, K., \& KUKLA, C. (2002). Just-in-time contextsensitive questioning for preventative health care. In Proceedings of the AAAI 2002 Workshop on Automation as Caregiver: The role of intelligent technology in elder care (AAAI Tech. Rep. WS-02-02, pp. 54-59). Menlo Park, CA: AAAI Press. 
INTILle, S. S., Rondon, J., KuKLA, C., IACONO, I., \& BAO, L. (2003). A context-aware experience sampling tool. In Proceedings of the Conference on Human Factors in Computing Systems: Extended abstracts (pp. 972-973). New York: ACM Press.

JoHnson, S. M., \& BolsTAD, O. D. (1973). Methodological issues in naturalistic observation: Some problems and solutions for field research. In L. A. Hamerlynch, J. C. Handy, \& E. J. Marsh (Eds.) Behavior change: Methodology, concepts, and practice (pp. 7-67). Champaign, IL: Research Press.

KAlbfleisCh, J. D., \& Prentice, R. L. (2002). The statistical analysis of failure time data (2nd ed.). New York: Wiley.

KAzDIN, A. E. (1979a). Direct observations as unobtrusive measures in treatment evaluation. In L. Sechrest (Eds.), Unobtrusive measurement today: New directions for methodology of behavioral science (pp. 19-31). San Francisco: Jossey-Bass.

KAZDIN, A. E. (1979b). Unobtrusive measures in behavioral assessment. Journal of Applied Behavior Analysis, 12, 713-724.

KAZDIN, A. E. (1982). Observer effects: Reactivity of direct observation. In D. P. Hartmann (Ed.), Using observers to study behavior: New directions for methodology of social and behavioral science (pp. 5-19). San Francisco: Jossey-Bass.

KAzDIN, A. E. (1992). Research design in clinical psychology (2nd ed.). Needham Heights, MA: Allyn \& Bacon.

KENT, R. N., \& FosteR, S. L. (1977). Direct observational procedures: Methodological issues in naturalistic settings. In A. R. Ciminero, K.S. Calhoun, \& H. E. Adams (Eds.), Handbook of behavioral assessment (pp. 279-328). New York: Wiley.

KERN, N., \& SCHIELE, B. (2003). Context-aware notification for wearable computing. In Proceedings of the 7th International Symposium on Wearable Computing (pp. 223-230). Los Alamitos, CA: IEEE Computer Society Press.

Kessler, R. C., Berglund, P., Demter, O., Jin, R., Merikangas, K. R., \& WALTERS, E. E. (2005). Lifetime prevalence and age-of-onset distributions of $D S M-I V$ disorders in the national comorbidity survey replication. Archives of General Psychiatry, 65, 593-603.

KIDD, C. D., OrR, R., ABOWd, G. D., ATKESON, C. G., Essa, I. A., MACINTYRE, B., ET AL. (1999). The Aware Home: A living laboratory for ubiquitous computing research. In N. A. Streita, J. Siegel, V. Harkopf, \& S. Konomi (Eds.), Cooperative buildings: Integrating information, organizations, and architecture. Proceedings of the Second International Workshop, CoBuild'99 (pp. 191-198). Berlin: Springer.

KNIGHT, J. F., BABER, C., SCHWIRTZ, A., \& BrISTOW, H. W. (2002). Comfort assessment of wearable computers. In $\mathbf{M}$. Billinghurst (Ed.), The Sixth International Symposium on Wearable Computers (pp. 65-72). Los Alamitos, CA: IEEE Computer Society Press.

KoROTITSCH, W. J., \& Nelson-GraY, R. O. (1999). An overview of selfmonitoring research in assessment and treatment. Psychological Assessment, 11, 415-425.

LAMEY, A., HollensTEIN, T., LEWIS, M. D., \& GRANIC, I. (2004). GridWare (Version 1.1) [Computer software]. Available at statespacegrids.org.

LAMIELL, J. T. (1981). Toward an idiothetic psychology of personality. American Psychologist, 36, 276-289.

LAMIELL, J. T. (1987). The psychology of personality: An epistemological inquiry. New York: Columbia University Press.

LAMIELL, J. T. (2003). Beyond individual and group differences: Human individuality, scientific psychology, and William Stern's critical personalism. Thousand Oaks, CA: Sage.

LAWLESS, J. F. (2002). Statistical models and methods for lifetime data (2nd ed.). New York: Wiley.

LEE, E. T., \& WANG, J. W. (2003). Statistical methods for survival data analysis (3rd ed.). New York: Wiley.

LEPINE, J. (2002). The epidemiology of anxiety disorders: Prevalence and societal costs. Journal of Clinical Psychiatry, 63, 4-8.

LEWIS, M. H., \& BoDFISH, J. W. (1998). Repetitive behavior disorders in autism. Mental Retardation \& Developmental Disabilities Reseanch Reviews, 4, 80-89.

LINDSEY, J. K. (1999). Models for repeated measurements (2nd ed.). Oxford: Oxford University Press.

LuPINSKI, D., \& NELSON, R. (1974). Problems in the use of naturalistic observation as a means of behavioral assessment. Behavior Therapy, $5,341-351$.

LORD, C., \& PAUL, R. (1997). Language and communication in autism.
In D. Cohen \& F. Volkmar (Eds.), Handbook of autism and pervasive developmental disorders (pp. 195-225). New York: Wiley.

Margraf, J., TAYlor, C. B., Ehlers, A., Roth, W. T., \& Agras, W. S. (1987). Panic attacks in the natural environment. Journal of Nervous \& Mental Disease, 175, 558-565.

MCDONNELL, P. J., \& JACOBS, M. R. (2002). Hospital admissions resulting from preventable adverse drug reactions. Annals of Pharmacotherapy, 36, 1331-1336.

MCGRATH, J. E., \& TsCHAN, F. (2004). Temporal matters in social psychology: Examining the role of time in the lives of groups and individuals. Washington, DC: American Psychological Association.

Mehl, M. R., Pennebaker, J. W., Crow, D. M., Dabes, J., \& Price, J. H. (2001). The Electronically Activated Recorder (EAR): A device for sampling naturalistic daily activities and conversations. Behavior Research Methods, Instruments, \& Computers, 33, 517-523.

MolenaAR, P. C. M. (2004). A manifesto on psychology as idiographic science: Bringing the person back into scientific psychology, this time forever. Measurement, 2, 201-218.

MolenaAr, P. C. M., Huizenga, H. M., \& Nesselroade, J. R. (2003). The relationship between the structure of interindividual and intraindividual variability: A theoretical and empirical vindication of developmental systems theory. In U. M. Staudinger \& U. Lindenberger (Eds.), Understanding human development: Dialogues with lifespan psychology (pp. 339-360). Boston: Kluwer.

MOORE, G. E. (1965). Cramming more components onto integrated circuits. Electronics, 38, 1-4.

MuNDY, P., \& STELLA, J. (2000). Joint attention, social orienting, and communication in autism. In A. M. Wetherby \& B. M. Prizant (Eds.), Autism spectrum disorders: A transactional developmental perspective (pp. 55-78). Baltimore: Brookes.

Munguia Tapta, E., Intille, S. S., \& Larson, K. (2004). Activity recognition in the home setting using simple and ubiquitous sensors. In A. Ferscha \& F. Mattern (Eds.), Proceedings of PERVASIVE 2004 (Vol. LNCS 3001, pp. 158-175). Berlin: Springer.

MUTHÉN, B. (2001). Second-generation structural equation modeling with a combination of categorical and continuous latent variables: New opportunities for latent class/latent growth modeling. In L. M. Collins \& A. G. Sayer (Eds.), New methods for the analysis of change (pp. 291-322). Washington, DC: American Psychological Association.

NAGIN, D. (1999). Analyzing developmental trajectories: A semiparametric, group-based approach. Psychological Methods, 4, 139-157.

NATIONAL Institute ON AlCOHOL ABUSE AND ALCOHOLISM (2000). Tenth special report to the U.S. Congress on Alcohol and Health. Bethesda, MD: Author.

NATIONAL INSTITUTES OF HEALTH (1998). Clinical guidelines on identification, evaluation, and treatment of overweight and obesity in adults (Pub. 98-4083). Bethesda, MD: National Institutes of Health, National Heart, Lung, and Blood Institute.

NeIsSER, U. (1976). Cognition and reality. San Francisco: Freeman.

Nelson-Gray, R. O. (1996). Treatment outcome measures: Nomothetic or idiographic? Clinical Psychology: Science \& Practice, 3, 164-167.

Nesselroade, J. R., \& GHisletTA, P. (2003). Structuring and measuring change over the lifespan. In U. U. Staudinger \& U. Lindenberger (Eds.), Understanding human development: Dialogues with lifespan psychology (pp. 317-337). Boston: Kluwer.

Newschaffer, C. J., \& Curran, L. K. (2003). Autism: An emerging public health problem. Public Health Reports, 118, 393-399.

Nusser, S. M., INTILLE, S. S., \& MaITRA, R. (2006). Emerging technologies and next-generation intensive longitudinal data collection. In T. A. Walls \& J. L. Schafer (Eds.), Models for intensive longitudinal data (pp. 254-277). Oxford: Oxford University Press.

O'Hara, K., Morrus, R., Shadbolt, N., Hitch, G. J., Hall, W., \& BeAGRIE, N. (2006). Memories for life: A review of the science and technology. Journal of the Royal Society Interface, 3, 351-365.

ORR, R. J., \& ABOwD, G. D. (2000). The smart floor: A mechanism for natural user identification and tracking. In $\mathrm{CHI}$ '00: Extended abstracts on human factors in computing systems (pp. 275-276). New York: ACM Press.

Osterberg, L., \& Blaschke, T. (2005). Drug therapy: Adherence to medication. New England Joumal of Medicine, 353, 487-497.

PATterson, D. R., \& SeChrest, L. (1983). Nonreactive measures in 
psychotherapy outcome research. Clinical Psychology Review, 3, $391-416$.

Peña, D., Thao, G. C., \& Tsay, R. S. (2001). A course in time series analysis. New York: Wiley.

Pentland, A. P. (1996). Smart rooms. Scientific American, 274, 68-75.

Pentland, A. P. (2005). Healthwear: Medical technology becomes wearable. Studies in Health Technology \& Informatics, 118, 55-65.

Pervin, L. A. (1984). Idiographic approaches to personality. In N. S. Endler \& J. M. Hunts (Eds.), Personality and the behavior disonders (pp. 261-282). New York: Wiley.

PICARD, R. W. (1997). Affective computing. Cambridge, MA: MIT Press.

PoLI, A. (2003). The equipped body: Wearable computers and intelligent fabrics. In L. Fortunati, J. E. Katz, \& R. Riccini (Eds.), Mediating the human body: Technology, communication, and fashion (pp. 169-173). Mahwah, NJ: Erlbaum.

PrIOR, M., \& Ozonoff, S. (1998). Psychological factors in autism. In F. R. Volkmar (Ed.), Autism and pervasive developmental disorders (pp. 64-108). Cambridge: Cambridge University Press.

RaPee, R. M., Craske, M. G., \& Barlow, D. H. (1990). Subjectdescribed features of panic attacks using self-monitoring. Journal of Anxiety Disonders, 4, 171-181.

RIVLIN, A., \& WIENER, J. (1988). Caring for the disabled elderty: Who will pay? Washington, DC: Brookings Institute.

RosenBerg, M. J. (1969). The conditions and consequences of evaluation apprehension. In R. Rosenthal \& R. L. Rosnow (Eds.), Artifact in behavional research (pp. 279-349). New York: Academic Press.

Rudd, P., BYyny, R. L., Zachary, V., LoVerde, M. E., Titus, C., MrTChELL, W. D., \& MARShaLL, G. (1989). The natural history of medication compliance in a drug trial: Limitations of pill counts. Clinical Pharmacotherapy \& Therapeutics, 46, 169-176.

SAfren, S. A., OtTo, M. W., Worth, J. L., SAlomon, E., Johnson, W. MAYER, K., \& Boswell, S. (2001). Two strategies to increase adherence to HIV antiretroviral medication: Life-steps and medication monitoring. Behavior Reseanch Therapy, 39, 1151-1162.

SCHMUCKLER, M. A. (2001). What is ecological validity? A dimensional analysis. Infancy, 2, 419-436.

Scollon, C. N., Km-Prieto, C., \& Diener, E. (2003). Experience sampling: Promises and pitfalls, strengths and weaknesses. Journal of Happiness Studies, 4, \$-34.

SHADISH, W. R., COOK, T. D., \& CAMPBELL, D. T. (2002). Experimentat, and quasi-experimental designs for generalized causal inference. Boston: Houghton Mifflin.

SHIFFMAN, S. (2000). Real-time self-report of momentary states in the natural environment: Computerized ecological momentary assessment. In A. A. Stone, J. S. Turkkan, C. A. Bachrach, J. P. Jobe, H. S. Kutzman, \& V. S. Cain (Eds.), The science of self-report: Implications for research and practice (pp. 277-296). Mahwah, NJ: Erlbaum.

Silvia, P. J. (2002). Self-awareness and emotional intensity. Cognition \& Emotion, 16, 195-216.

SINGER, J. D., \& WILLETT, J. B. (2003). Applied longitudinal data analysis. Oxford: Oxford University Press.

Stager, M., Lukowicz, P., Perera, N., von Buren, T., Troster, G., \& STARNER, T. (2003). Soundbutton: Design of a low power wearable audio classification system. In Proceedings of the 7th IEEE International Symposium on Wearable Computers (ISWC'03) (pp. 12-17). Los Alamitos, CA: IEEE Computer Society Press.

STARNER, T. E. (2001). The challenges of wearable computing: Part 1. In IEEE wearable computing (pp. 44-52). Los Alamitos, CA: IEEE Computer Society Press.

STARNER, T. E. (2002). Wearable computers: No longer science fiction. In IEEE Pervasive Computing, 1, 86-88.

Stone, A. A., \& Shifrman, S. (1994). Ecological momentary assessment (EMA) in behavioral medicine. Annals of Behavioral Medicine, 16, 199-202.

Sung, M., Marci, C., \& Pentland, A. (2005). Wearable feedback systems for rehabilitation [Abstract]. Journal of NeuroEngineering \& Rehabilitation, 2, 17.

Tennen, H., Afrleck, G., \& ARMeli, S. (2003). Daily processes in health and illness. In J. Suls \& K. A. Wallston (Eds.), Social psychological foundations of health and illness (pp. 495-529). Malden, MA: Blackwell.

Tennen, H., Suls, J., \& Afrleck, G. (1991). Personality and daily ex- perience: The promise and the challenge. Journal of Personality, 59, 313-337.

TheODORIDIS, S., \& Koutroumbas, K. (2006). Pattern recognition. London: Academic Press.

Tuldrd, A., Fumaz, C. R., Ferrer, M. J., Bayés, R., Amó, A., BalaguE, M., Et Al. (2000). Prospective randomized two-arm controlled study to determine the efficacy of a specific intervention to improve long-term adherence to highly active antiretroviral therapy. Journal of Acquired Immune Deficiency Syndromes, 25, 221-228.

United Nations Population Division (2001). United Nations, world population prospects: The 2000 revision highlights. Available at www .un.org/esa/population/publications/wpp2000.

URQUHART, J. (1994). Role of patient compliance in clinical pharmacokinetics: A review of recent research. Clinical Pharmacokinetics, 27, 202-215.

URQUHART, J., \& DE KLERK, E. (1998). Contending paradigms for the interpretation of data on patient compliance with therapeutic drug regimens. Statistics in Medicine, 17, 251-267.

VeLICER, W. F., \& FAVA, J. (2003). Time series analysis. In J. A. Schinka \& W. F. Velicer (Eds.), Handbook of psychology: Research methods in psychology (Vol. 2, pp. 581-606). New York: Wiley.

VertegaAl, R., SlaGter, R., VAN DER VeER, G., \& NuHOlt, A. (2001). Eye gaze patterns in conversations: There is more to conversational agents than meets the eyes. In Proceedings of Human Factors in Computing Systems (CHI 2001) (pp. 301-308). New York: ACM Press.

WALLS, T. A., HÖPPNER, B. B., \& GOODWIN, M. S. (2007). Statistical issues in intensive longitudinal data analysis. In A. Stone, S. Shiffman, A. Atienza, \& L. Nebeling (Eds.), The science of real-time data capture: Self-reports in health research (pp. 338-360). Oxford: Oxford University Press.

WALLS, T. A., \& SCHAFER, J. L. (2006). Models for intensive longitudinal data. Oxford: Oxford University Press.

Webb, E. J., Campbell, D. T., Schwartz, R. D., Sechrest, L., \& Grove, J. B. (1981). Nonreactive measures in the social sciences. Boston: Houghton Mifflin.

WEISER, M. (1991). The computer for the 21 st century. Scientific America, 265, 94-104.

Wilhelm, F. H., Alpers, G. W., Meuret, A. E., \& Roth, W. T. (2001). Respiratory pathophysiology of clinical anxiety outside the laboratory: Assessment of end-tidal $\mathrm{pCO}_{2}$, respiratory pattern variability, and transfer function RSA. In J. Fahrenberg (Ed.), Progress in ambulatory assessment (pp. 313-343). Göttingen: Hogrefe \& Huber.

WILHELM, F. H., Roth, W. T., \& SACKNER, M. A. (2003). The LifeShirt: An advanced system for ambulatory measurement of respiratory and cardiac function. Behavior Modification, 27, 671-691.

WILSON, K. C. M., HopKINS, R., DE VRIES, M. W., \& Copeland, J. R. M. (1992). Research alliance and the limit of compliance: Experience sampling with the depressed elderly. In M.W. de Vries (Ed.), The experience of psychopathology: Investigating mental disorders in their natural settings (pp. 339-346). Cambridge: Cambridge University Press.

Wrtren, I. H., \& Frank, E. (1999). Data mining: Practical machine learning tools and techniques with Java implementations. San Francisco: Morgan Kaufimann.

Yeargin-Allsopp, M., Rice, C., Karapurkar, T., Dotrnberg, N., BOYLE, C., \& MURPHY, C. (2003). Prevalence of autism in a US metropolitan area. Journal of the American Medical Association, 289, 49-55.

\section{NOTES}

1. Radio frequency identification (RFID) is a generic term for technologies that use radio waves to automatically identify objects. Identification is most commonly achieved by storing a unique serial number that identifies an object on a microchip with an embedded antenna. The antenna enables the chip to transmit the identification information to a reader. The reader converts the radio waves reflected back from the RFID tag into digital information that can then be transmitted to a computer.

2. O'Hara et al. (2006) have predicted that advances in memory storage will enable digital memory over a human lifetime. Gemmell, Bell, Lueder, Drucker, and Wong (2002) have predicted that a terabyte of memory will retail for less than $\$ 300$ in 5 years. 